\title{
Morphological study of placenta in hypertensive disorders in pregnancy
}

\author{
Bar P. K. ${ }^{1}$, Ghosh S. ${ }^{2}$, Gayen P. ${ }^{3}$, Mandal S. ${ }^{4}$, De (Pati) A. ${ }^{5}$, Biswas A $^{6}$ \\ ${ }^{1}$ Dr. Prasenjit Kumar Bar, Assistant Professor, ${ }^{2}$ Dr. Saswata Ghosh, Assistant Professor, ${ }^{3}$ Dr. Prosenjit Gayen, Assistant \\ Professor, ${ }^{4}$ Dr Saikat Mandal, Demonstrator; ${ }^{1,2,3,4}$ author are affiliated with Malda Medical College. ${ }^{5}$ Dr. Anuradha De \\ (Pati), Associate Professor, School of Tropical Medicine, Kolkata. ${ }^{6}$ Aditi Biswas, Assistant Teacher, Mollarpur Girls' \\ High School, Birbhum, West Bengal, India.
}

Corresponding Author: Dr. Prosenjit Gayen, Assistant Professor, Malda Medical College, Malda, West Bengal, India. E-mail: prosenjitdr@gmail.com

\begin{abstract}
Introduction: Hypertensive disorders are common complications of pregnancy. Thorough macroscopic and microscopic examination of the placenta provides much insight into the prenatal health of the baby and the mother. Objectives: 1. To study the morphological changes in the placenta in pregnant mothers. 2. Comparative study of morphological changes in the placenta among hypertensive and normotensive pregnant mothers. Methods: An Observational Prospective Cohort Study was performed. Detail clinical history taken and placentae were collected from both 40 hypertensive and 40 normotensive mother's delivered in labour room or operation theatre. Both macroscopical and histopathological examination was done. Findings were recorded and analyzed statistically. Results: The comparison of placental diameter, placental thickness, mean placental weight, placental volume, placental surface area between hypertensive and normotensive group showed statistically significant difference ( $\mathrm{p}$ value $<0.05$ ). Incidence of placental haematoma, infarction, basement membrane thickening of villi and syncytial knot in hypertensive group was $20 \%, 27.5 \%, 50 \%$ and $92.5 \%$ \& in normotensive group was $5 \%, 10 \%, 12 \%$ and $60 \%$ respectively. All cases in hypertensive group had placental fibrinoid necrosis of villi in comparison to $57.5 \%$ cases in normotensive group $(p<0.05)$. For fibrosis of villi and cytotrophoblatic proliferation $\mathrm{p}$ value was $<0.05$ which was statistically significant. Conclusion: Effects of hypertensive disorder in pregnancy reflect in gross and microscopic findings of placenta which may contribute to the further management of mother and baby.
\end{abstract}

Key words: Hypertensive Disorders, Morphology, Placenta, Pregnancy

\section{Introduction}

Hypertensive disorders are common complications of pregnancy. How pregnancy initiates or aggravates hypertension remains unsolved despite decades of intensive research. Most adverse events like maternal and neonatal mortality and morbidity are attributable directly to the preeclampsia syndrome, characterized by new-onset hypertension with proteinuria during pregnancy [1].

Hypertensive disorders during pregnancy are classified into 4 categories, as recommended by the National High Blood Pressure Education Program Working Group on High Blood Pressure in Pregnancy: 1) chronic hypertension, 2) preeclampsia- eclampsia,

Manuscript received: $20^{\text {th }}$ May 2019

Reviewed: $30^{\text {th }}$ May 2019

Author Corrected: $4^{\text {th }}$ June 2019

Accepted for Publication: $9^{\text {th }}$ June 2019
3) preeclampsia superimposed on chronic hypertension, and 4) gestational hypertension (transient hypertension of pregnancy or chronic hypertension identified in the latter half of pregnancy) [2]. A pregnant woman with a blood pressure of less than $140 / 90 \mathrm{mmHg}$, throughout the pregnancy, is considered as normotensive [3].

Intrauterine existence of the fetus is dependent on the vital organ 'The Placenta' [4]. If the placenta is examined minutely it provides much insight into the prenatal health of the baby and the mother. It is the vital organ for maintaining pregnancy and promoting normal fetal development. Placenta is a mirror, which reflects the intrauterine status of the fetus [5]. It has been recorded that maternal utero-placental blood flow is decreased in pre-eclampsia, because there is maternal vasospasm [6,7]. Maternal vasospasm leads to fetal hypoxia. 
Fetal hypoxia is not uncommon near term and it may lead to fetal distress and fetal death [8]. Reduced maternal utero-placental blood flow leading indirectly to constriction of fetal stem arteries, has been associated with the changes seen in the placentae of preeclamptic women [9]. Placentae from pregnancies complicated by preeclampsia had significantly lower total volumes of parenchyma and villous surface area when compared with normal pregnancies of comparable gestation [10]. Minor areas of infarctions are seen in about $25 \%$ of placentae from normal pregnancies. Extensive placental infarction is usually seen in placentae from preeclamptic mothers [3]. Placenta from preeclamptic mothers tend to be, on average, smaller than those in uncomplicated pregnancies and infarcts are more numerous, larger and often centrally located [11].

Histopathological findings like cytotrophoblastic cellular proliferation; syncytial knot formation, fibrin plaque formation etc. were present in greater amount in hypertensive placentae [10].

\section{Objectives}

Examination of the placenta can yield information that may be important in the immediate and later management of the mother and the infant. This information may also be essential for protecting the attending physician in the event of an adverse maternal or fetal outcome. Universal examination of the placenta in the delivery room, with documentation of findings and submission of tissue for pathologic evaluation based on abnormal appearance or certain clinical indications, is standard medical practice [12].

With this preamble the study was carried out with the following objectives:

1. To study the morphological changes in the placenta in pregnant mothers.

2. Comparative study of morphological changes in the placenta among hypertensive and normotensive pregnant mothers.

\section{Materials and Methods}

Study type: Observational study.

Study design: Prospective Cohort Study.

Study setting/area, Population and period: The study was performed on pregnant women attending in the Department of Pathology \& Department of Gynaecology and Obstetrics of North Bengal Medical College \& Hospital, Sushrutanagar, Darjeeling during the period of $1^{\text {st }}$ March 2008 to $28^{\text {th }}$ February 2009 (One year).

\section{Original Research Article}

Sampling

Selection of cohort of hypertensive and normotensive pregnant mothers: A cohort of pregnant women having hypertension (Blood Pressure (BP) $\geq 140 / 90 \mathrm{~mm} \mathrm{Hg}$ ), was selected from the patients attending the antenatal clinic in the Department of Obstetrics \& Gynaecology, North Bengal Medical College \& Hospital.

A total of 55 patients were selected. Out of 55 selected hypertensive cohorts, 40 patients fulfill the inclusion and exclusion criteria at the time of delivery and thereafter in the postnatal period of more than 12 weeks. Normotensive cohort of pregnant women was selected randomly from antenatal clinic after applying inclusion and exclusion criteria for selection. Total 50 normotensive pregnant mothers were selected. Out of 50 selected normotensive patients, 40 were traced at the time of delivery and thereafter fulfilling the criteria for inclusion and exclusion and the placentae were collected.

Inclusion criteria: The pregnant mothers in the age group 20 years to 40 years attended for antenatal check up. Patients having detailed history, clinical data, consent $\&$ cooperation of patients, blood \& urine report $\&$ specimen of placenta available for examination.

Pregnant women having hypertension (blood pressure (BP) $\geq 140 / 90 \mathrm{~mm} \mathrm{Hg}$ ). Normotensive (blood pressure of less than $140 / 90 \mathrm{mmHg}$ ) pregnant mothers without any illness. Specimen of placenta collected from the full term delivery cases (i.e, cases completed 37 weeks of gestation)

Exclusion criteria: Patients with age below 20 years and above 40 years. Other Medical or Surgical illness. Blood \& urine report and consent not available and patients lost or missing in the follow-up period.

\section{Study Techniques}

1. Case history and clinical examination

2. Collection of the specimen

3. Examination of the specimen

4. Follow-up

5. Statistical Analysis

Techniques in detail: It includes clinical study of the cases and examination of placenta after delivery as described below:

1. Detail Case history including LMP recorded and Clinical examination done

2. Collection of the specimen. 
Fresh placentae were collected at labor room /Operation theatre, labeled and sent to Pathology Department.

Examination of the specimen: Examinations of placenta were conducted according to proforma adopted by Benirschke and later modified by Woodly et al [13].

Gross examination: Following parameters of the placenta were determined:-

dimensions, surface area, weight, volume, shape, examination of the fetal surface, insertion of the umbilical cord and amniotic membranes. Examination of the maternal surface, blood clots, infarcts, number of cotyledon and examination of cut sections.

Microscopic examination: Documentation of most of the findings found in light microscopic were tabulated as present or absent or nil. Placental infarcts were grouped in the following manner:

\section{Original Research Article}

Absent $=0$, infarction involving less than $5 \%$ of villous parenchyma $=1, \quad$ infarcts involving $5-10 \%$ parenchyma $=2$ and infarcts involving more than $10 \%$ of the villous parenchyma $=3[7]$

Histopathological parameters studied: Maximum possible fields of each slides were examined to find out the following- Infarction, Fibrinoid Necrosis of Villi, Thrombosis of Fetal Artery, Basement membrane Thickening of Villi, Fibrosis of Villi, Cytotrophoblastic Proliferation and Syncytial Knots:

Statistical Analysis: Statistical Analysis was done by using Epi-Info software Version 3.3.2 .Statistical Tests (Pearson Chi-square Test, Independent Samples Test) were applied whenever it was necessary. For significance $\mathrm{p}$-value $<0.05$ was taken. Incidence, Relative risk (RR) \& Attributable risks (AR) were measured from the observations of the study.

\section{Result}

Among the 55 hypertensive pregnant mothers and 50 normotensive pregnant mothers, 40 mothers in each group were studied. And they were grouped as-

Group I= Hypertensive pregnant mothers

Group II= Normotensive pregnant mothers

In both these groups, age of the patients ranged from 20 to 32 years and both were delivered at term pregnancy. Mean Age $=22.35$ years \pm 3.026 (S.D.) in hypertensive group and 23.23 years \pm 2.636 (S.D.) in normotensive group. Maximum number 27 (67.5\%) of hypertensive mothers belonged to gestational hypertension type.

Mean birth weight of baby in hypertensive and normotensive groups was 2.4538 kilogram \pm 0.19693 (S.D) and 2.7423 kilogram \pm 0.14430 (S.D) respectively. Normotensive group had $95 \%$ normal birth weight in comparison to hypertensive group, which was $62.5 \%$.

Placental Morphology: Macroscopic: Most common shape was round found in $62.5 \%$ of the placenta in normotensive mothers and $57.5 \%$ of the placenta in hypertensive mothers. Shapes of the placenta have got no statistical significance (pvalue $=0.648)$.

Mean placental diameter among hypertensive (Fig.1) and normotensives was $15.39 \mathrm{~cm} \pm 0.535$ (S.D.) and $17.91 \mathrm{~cm} \pm$ 0.982 (S.D.) respectively (i.e. lower values in hypertensive group). The comparison showed statistically significant difference ( $\mathrm{p}$ value $<0.05$ ). Mean placental thickness among the hypertensive group was $2.10 \mathrm{~cm} \pm 0.431$ (S.D) and 2.29 $\mathrm{cm} \pm 0.282$ (S.D) among the normotensvive group (i.e. lower values in hypertensive group). The difference was found to be statistically significant in between the groups. $p=0.024(<0.05)$.

Table-1: Showing comparison of mean placental weight between hypertensive and normotensive group.

\begin{tabular}{|c|c|c|c|c|c|c|}
\hline \multirow{3}{*}{$\begin{array}{l}\text { Placental } \\
\text { Weight } \\
\text { (Gm) }\end{array}$} & $\begin{array}{c}\text { Study } \\
\text { population }\end{array}$ & $\begin{array}{c}\text { No. of } \\
\text { cases }\end{array}$ & Mean & $\begin{array}{c}\text { Std. } \\
\text { Deviation }\end{array}$ & $\begin{array}{c}\text { Std. Error } \\
\text { Mean }\end{array}$ & Significance \\
\hline & $\begin{array}{c}\text { Group I } \\
\text { (Hypertensive) }\end{array}$ & 40 & 377.00 & \pm 12.079 & 1.910 & \multirow{2}{*}{$\begin{array}{c}\mathrm{df}=78 \\
\mathrm{t}=25.319 \\
\mathrm{P}=0.000 \\
(<0.05)\end{array}$} \\
\hline & $\begin{array}{c}\text { Group II } \\
\text { (Normotensive) }\end{array}$ & 40 & 476.88 & \pm 21.829 & 3.452 & \\
\hline
\end{tabular}

Mean placental weight (table1) among hypertensive and normotensive groups was $377.00 \mathrm{gm} \pm 12.079$ (S.D) and 476.88 $\mathrm{gm} \pm 21.829$ (S.D) respectively (lower in hypertensive group) and the difference was found to be statistically significant. $P$ value $=0.000(\mathrm{p}<0.05)$. 
Original Research Article

Table-2: Showing comparison of mean placental volume between hypertensive and normotensive group.

\begin{tabular}{|c|c|c|c|c|c|c|}
\hline \multirow{3}{*}{$\begin{array}{l}\text { Placental } \\
\text { Volume (ml) }\end{array}$} & $\begin{array}{c}\text { Study } \\
\text { population }\end{array}$ & $\begin{array}{l}\text { No. of } \\
\text { cases }\end{array}$ & Mean & $\begin{array}{c}\text { Std. } \\
\text { Deviation }\end{array}$ & $\begin{array}{l}\text { Std. Error } \\
\text { Mean }\end{array}$ & Significance \\
\hline & $\begin{array}{c}\text { Group I } \\
\text { (Hypertensive) }\end{array}$ & 40 & 362.25 & \pm 10.798 & 1.707 & \multirow{2}{*}{$\begin{array}{c}\mathrm{df}=78 \\
\mathrm{t}=43.995 \\
\mathrm{p}-\mathrm{value}=0.000 \\
(<0.05)\end{array}$} \\
\hline & $\begin{array}{c}\text { GroupII } \\
\text { (Normotensive) }\end{array}$ & 40 & 564.92 & \pm 27.061 & 4.279 & \\
\hline
\end{tabular}

Mean placental volume (table 2) was $362.25 \mathrm{ml} \pm 10.798$ (S.D) and $564.92 \mathrm{ml} \pm 27.061$ (S.D) in hypertensive and normotensive group respectively (i.e. lower placental volume in hypertensive group of mothers) and difference was statistically significant ( $\mathrm{p}$-value $=<0.05$ ). Mean placental surface area was $185.300 \mathrm{sq} . \mathrm{cm} \pm 12.588$ (S.D) and 252.404 sq. $\mathrm{cm} . \pm 27.464$ (S.D) in hypertensive and normotensive group respectively which was found to be statistically significant (p- value $<0.05)$. Incidence of placental macroscopic infarction $(27.5 \%)$ in group $1 \& 7.5 \%$ in group II, the difference was found to be statistically significant, p-value $=0.019(<0.05)$. Relative risk was 3.67 and Attributable risk was 72.72 $\%$, it indicates $72.72 \%$ of placental macroscopic infarction was due to hypertension in pregnancy. Incidence of placental haematoma was $20 \%$ in hypertensive group and $5 \%$ in normotensive group, 4 times (relative risk = 4) raised in hypertensive group than the normotensive group, the difference was significant statistically. Relative risk of placental haemtoma $(\mathrm{RR})=20 \% / 5 \%=4$ and Attributable risk of placental haematoma $=(20-5) / 20 \mathrm{X} 100 \%=75 \%$ which indicates $75 \%$ of placental haematoma due to hypertensive disorders in pregnancy.

\section{Placental Morphology: Microscopic}

Table-3: Showing comparison of different placental infarction groups between hypertensive and normotensive group.

\begin{tabular}{|c|c|c|c|c|c|}
\hline \multirow{2}{*}{ Study Group } & \multicolumn{3}{|c|}{ Infarction } & \multirow{2}{*}{ Total } & \multirow{2}{*}{ Significance } \\
\hline & Group 0 & Group 1 & Group 2 & & \\
\hline Hypertensive & $\begin{array}{c}29 \\
(72.5 \%)\end{array}$ & $\begin{array}{c}5 \\
(12.5 \%)\end{array}$ & $\begin{array}{c}6 \\
(15.0 \%)\end{array}$ & $\begin{array}{c}40 \\
(100.0 \%)\end{array}$ & \multirow{3}{*}{$\begin{array}{c}\text { Pearson } \\
\text { Chi-Square } \\
\text { Value }=6.865 \\
\mathrm{p}=0.032 \\
\mathrm{df}=2 \\
\mathrm{RR}=2.75 \\
\mathrm{AR}=63.6 \%\end{array}$} \\
\hline Normotensive & $\begin{array}{c}36 \\
(90.0 \%)\end{array}$ & $\begin{array}{c}4 \\
(10.0 \%)\end{array}$ & $\begin{array}{c}0 \\
0 \%\end{array}$ & $\begin{array}{c}40 \\
(100.0 \%)\end{array}$ & \\
\hline Total & $\begin{array}{c}65 \\
(81.3 \%)\end{array}$ & $\begin{array}{c}9 \\
(11.3 \%)\end{array}$ & $\begin{array}{c}6 \\
(7.5 \%)\end{array}$ & $\begin{array}{c}80 \\
(100.0 \%)\end{array}$ & \\
\hline
\end{tabular}

Placental infarction grouped when infarction was absent $=0$, involving $<5 \%$ of villous parenchyma $=1$, involving $5-$ $10 \%$ parenchyma $=2$ ) $[3]$.

Incidence of Infarction (Fig. 2) among hypertensive mothers $=27.5 \%$ in comparison to $10 \%$ in normotensive mothers. Relative risk $=27.5 / 10=2.75$ and Attributable risk $=(27.5-10) / 27.5 \times 100=(17.5 / 27.5) \times 100=3.63 \%$. It indicates that $63.63 \%$ of placental infarction due to hypertensive disorders in pregnancy. (Table 3 )

- Group 1 ( $<5 \%$ villous parenchyma involvement) infarction=10\% in normotensives \& $4.2 \%$ in mild hypertensives

- In mild hypertension group 1 and group 2 infarction $=4.2 \%$

- In severe hypertension group 1 and group 2 infarction $=25 \%+37.5 \%=62.5 \%$

- Severity of infarction had significant relation with the type of hypertension in between the groups $(\mathrm{p}<0.05)$.

Table-4: Showing comparison of fibrinoid necrosis of villi between hypertensive and normotensive group.

\begin{tabular}{|c|c|c|c|}
\hline $\begin{array}{c}\text { Fibrinoid } \\
\text { Necrosis of } \\
\text { villi }\end{array}$ & $\begin{array}{c}\text { Group1 } \\
\text { (Hypertensive } \\
\text { Group) }\end{array}$ & $\begin{array}{c}\text { Group II } \\
\text { (Normotensive } \\
\text { Group) }\end{array}$ & Significance \\
\hline Absent & 0 & 17 & Pearson Chi-Square Value $=$ \\
Present & $(0 \%)$ & 23 & 21.587, \\
& $(100 \%)$ & $(57.5 \%)$ & $\mathrm{df}=1$, \\
Total & $\mathbf{4 0}$ & $\mathbf{4 0}$ & $\mathrm{P}=0.000001(<0.05)$ \\
& $\mathbf{( 1 0 0 . 0 \% )}$ & $\mathbf{( 1 0 0 . 0 \% )}$ & $\mathrm{RR}=1.73$ \\
\end{tabular}




\section{Original Research Article}

All cases in hypertensive group had placental fibrinoid necrosis (Fig. 3 \& table 4) of villi in comparison to 57.5\% cases in normotensive. This was found to be statistically significant $(\mathrm{p}<0.05)$. Relative risk $=1.73$ and Attributable risk $=$ $42.5 \%$. It means $42.5 \%$ of placental fibrinoid necrosis was due to hypertensive disorders in pregnancy. Incidence of fetal artery thrombosis in hypertensive group was $10 \%$ and in normotensive groups was $2.5 \%$. Difference was not statistically significant. ( $\mathrm{p}$ value $>0.05$ )

Table-5: Showing comparison of basement membrane thickening of villi between hypertensive and normotensive group.

\begin{tabular}{|c|c|c|c|}
\hline $\begin{array}{l}\text { Basement Membrane } \\
\text { Thickening of villi }\end{array}$ & $\begin{array}{c}\text { Group1 } \\
\text { (Hypertensvie } \\
\text { group) }\end{array}$ & $\begin{array}{c}\text { GroupII } \\
\text { (Normotensive } \\
\text { group) }\end{array}$ & Significance \\
\hline Absent & $\begin{array}{c}20 \\
(50.0 \%)\end{array}$ & $\begin{array}{c}35 \\
(87.5 \%)\end{array}$ & \multirow{3}{*}{$\begin{array}{c}\text { Pearson Chi-Square } \\
\text { Value }=21.587 \quad \mathrm{df}=1, \\
\text { p- value }=0.000001 \\
(\mathrm{p}<0.05) \\
\mathrm{RR}=4 \\
\mathrm{AR}=75 \%\end{array}$} \\
\hline Present & $\begin{array}{c}20 \\
(50.0 \%)\end{array}$ & $\begin{array}{c}5 \\
(12.5 \%)\end{array}$ & \\
\hline Total & $\begin{array}{c}40 \\
(100.0 \%)\end{array}$ & $\begin{array}{c}40 \\
(100.0 \%)\end{array}$ & \\
\hline
\end{tabular}

Incidence of basement membrane thickening of villi in hypertensive (table 5) group was 50\% in comparison to normotensive group which was $12.5 \%$. It indicates significant increase in basement membrane thickening of villi, due to hypertensive disorders in pregnancy. Relative risk $=(R R)=50 \% / 12.5 \%=4$. There is 4 times increased risk of basement membrane thickening of villi in hypertensive group.

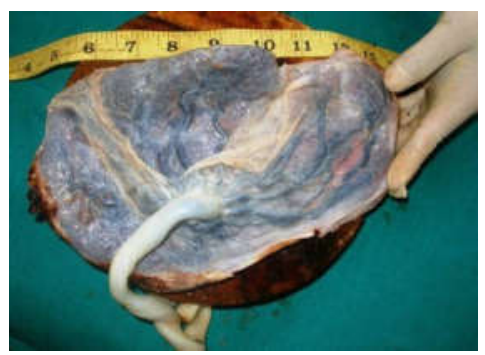

Fig.-1: Photomicrograph showing fetal surface of small irregular placenta of hypertensive mother (gross examination).

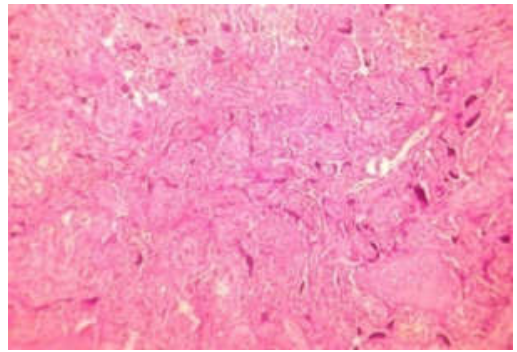

Fig.-2: Photomicrograph showing placental infarct (H \& E Stain x 40) of hypertensive mother

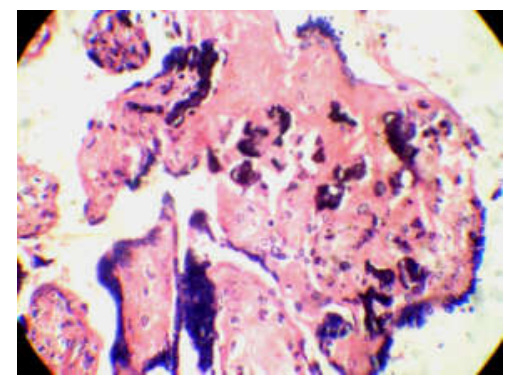

Fig.-3: Photomicrograph showing fibrinoid necrosis of villi, calcification \& syncytial knots (H \& E Stain x 40) of hypertensive mother 


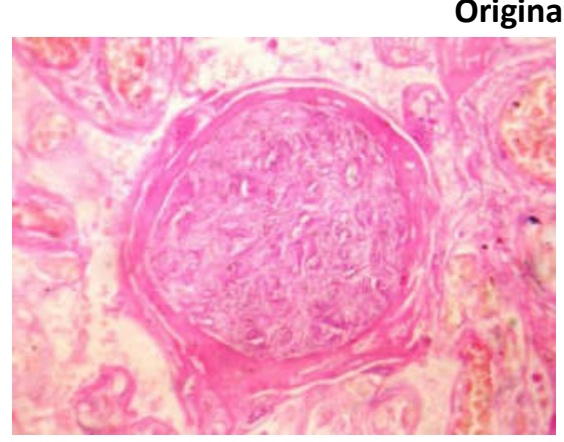

Fig.-4: Photomicrograph showing organized arterial thrombus (H \& E Stain $x$ 40) of hypertensive mother

Incidence of fibrosis of villi in hypertensive group was $95 \%$ and in normotensive group was $52.5 \%$, which was increased significantly in hypertensive group $(\mathrm{p}<0.05)$. Relative risk $(\mathrm{RR})$ of fibrosis of vill $=1.80$ and Attributable risk $(\mathrm{AR})=$ $44.73 \%$. It indicates $44.73 \%$ of fibrosis of villi due to hypertensive disorders in pregnancy. Incidence of cytotrophoblatic proliferation was $47.5 \%$ in hypertensive group and $22.5 \%$ in normotensive group. It means significant increased incidence in hypertensive group, $(\mathrm{p}<0.05)$ with relative risk $=2.11 .52 .63 \%$ increased chance of cytotrophoblastic proliferation is due to hypertension in pregnancy. Incidence of syncytial knot (Fig. 3) in hypertensive group was $92.5 \%$ and in normotensive group was $60 \%$ with relative risk of 1.54 and Attributable risk $=\mathrm{AR}=35.13 \%$. It means approximately $35 \%$ increase chance of syncytial knot was due to hypertensive disorders in pregnancy.

\section{Discussion}

Placenta being a fetal organ shares the same stress and strain, to which the fetus is being exposed. Thus any disease process affecting the mother and fetus also has a great impact on the placenta. Normally the placental morphology varies considerably during its short life span [4]. The placenta, which is functionally the most important and vital organ related to intrauterine life, is subjected to various defects and diseases just as the other vital organs of the body. Various clinical conditions such as anemia, diabetes, hypertension etc have a detrimental effect on the placenta, which in different degrees may seriously affect the health and even the life of the fetus.

Present study was conducted to examine both macroscopic and microscopic changes in placentas from hypertensive and normotensive mothers. Some variations were found to be very specific between the two groups but other changes were found which cannot be correlated between the two groups. The observations can be discussed according to the following headings:

In the present study mean birth weight of the baby in the hypertensive group of mothers was lower than the mean birth weight of the baby of normotensive group of mothers. Udainia et al observed decrease in the weight of newborn babies in PIH [4]. Similar findings we have found in our study.

Placental Morphology: Macroscopic- The diverse variations often proved difficult to differentiate a pathological placenta from a normal one.
In the present study most common shape was round $57.5 \%$ \& $62.5 \%$ in hypertensive \& normotensive groups respectively and found to be no statistically significant difference between the groups, $(p>0.05)$. According to Shah R. K. et al and Shanklin DR, shape may be round or oval and bears no correlation with maternal and fetal status - which supports our observation $[14,15]$.

Mean placental diameter (Fig.1) was statistically significant lower value in hypertensive groups, ( $\mathrm{p}$-value $<0.05$ ). According to Gray's Anatomy by Patrica C average placental diameter was $18.5 \mathrm{~cm}$, which was close to our observation in normotensive group and higher than the hypertensive group [16]. The difference in Mean placental thickness in our study was found to be statistically significant ( $\mathrm{p}-$ value $<0.05$ ) with lower thickness in hypertensive group. Patrica $\mathrm{C}$ in Grays Anatomy said thickness of the placenta was $2.3 \mathrm{~cm}$. which supports our observation in normotensive groups [16].

The placental weight (table 1) is the single most important factor reflecting fetal growth. Placental weight and Mean placental volume (table 2) in the present study found to be low in hypertensive group than that of normotensive which was statistically significant, $(\mathrm{p}<0.05)$. Majumder $\mathrm{S}$, and Dasgupta $\mathrm{H}$ found mean weight of the placenta was significantly lower in hypertensive group than normotensive group and Damania (1989), Fox (1994), and Kalousek (1994) also found lower values of placental volume in hypertensive than normotensive groups [10,17,18,19]. These mimic the observation of our study. 
Mean placental surface area in our study was 185.300 sq.cm \pm 12.588 (S.D) and 252.404 sq. cm. \pm 27.464 (S.D) respectively in hypertensive and normotensive groups. Udainia A, Bhagat SS, Mehta CD found that the mean surface area was significantly less in severe hypertension $\left(179.14 \mathrm{~cm}^{2}\right)$ and in mild hypertension $\left(195.98 \mathrm{~cm}^{2}\right)$ as compared to the control group ( 242.56 $\mathrm{cm}^{2}$ ) [5]. Majumder S and Dasgupta H, and Damania (1989), Fox (1994), and Kalousek (1994), had similar observation $[10,17,18,19]$.

Incidence of placental infarction was significantly high in hypertensive group $(\mathrm{p}<0.05)$. Mardi K, and Sharma $\mathrm{J}$, and Salgado SS et al. found significant increase in the incidence of infarction in placentae of hypertensive mothers compared to full term normal placentae $[20,21]$. In our study Incidence of retro-placental haematoma was significantly higher in hypertensive group with a relative risk of 4 . Fox H (1997) found 3 fold increase of retro-placental haematoma in placenta of preeclamptic mothers which mimics observation of our study [22].

Placental Morphology: Microscopic- In our study a significant increase in placental infarction (Fig. 2) in hypertensive group, $(p-$ value $<0.05)$ was found. These corroborate with the findings of Mardi K, and Sharma J, and Salgado SS et al [20,21]. Percentage of placental infarction (table 3) increases with the severity of hypertension with $62.5 \%$ involvement of villous parenchyma in severe hypertension. Fox H (1997) found similar incidence with approximately $60 \%$ involvement in patients of severe form of the disease [22].

All patients of hypertensive group show fibrinoid necrosis (Fig. 3) of villi in comparison to $57.5 \%$ in the normotensive group, statistically significant $(\mathrm{p}<0.05)$. (table 4) Incidence of fetal artery thrombosis in hypertensive group was $10 \%$ and in normotensive group was $2.5 \%$ noted in our study. Benirschke K, Kaufman $\mathrm{P}$, found thrombosis in $5 \%$ of placentae from normal pregnancies [23]. In our study mild increase in thrombosis was noted but without any statistical significance. Significant increase incidence of Basement membrane thickening of villi (table 5) was found in hypertensive group (50\%) in our study. Soma H.et aland Jones CJP and Fox $\mathrm{H}$ also found increased thickening of the basement membrane in placentae of hypertensive pregnancies, which supports our study $[24,25]$.

Incidence of fibrosis of villi, cytotrophoblastic proliferation and syncytial knots was increased significantly in hypertensive groups ( $\mathrm{p}$-value $<0.05$ ).

\section{Original Research Article}

Association fibrosis of villi with hypertensive diseases in pregnancy was mentioned in the book of Anderson's Pathology [26]. Jones CJP, Fox $\mathrm{H}^{\backslash}$ and Majumder S, and Dasgupta $H$ found significant increase in cytotrophoblastic proliferation in placenta of hypertensive group [10,25]. Tinney B Parker F and Majumder S, and Dasgupta $\mathrm{H}$ found increased or greater amount of syncytial knots in placentae of hypertensive pregnancies [10,27]. These findings support our observation.

\section{Conclusion}

Hypertensive disorders of pregnancy cause many adverse macroscopic and microscopic changes in placenta which may increase with the severity of the disease. These findings may help in the treatment of hypertensive mother and her offspring. Prevention of hypertension in pregnancy may decrease the incidence of fetal hypoxia and low birth weight. Furthermore these may protect the medical team in case of adverse pregnancy outcomes in patient who does not have proper history of prenatal checkup and present with emergency situation during delivery.

\section{Contribution by Authors}

1.Dr. Prasenjit Kumar Bar - Concept designing and conducting the study \& writing the manuscript.

2.Dr. Prosenjit Gayen, Dr. Saswata Ghosh, Dr. Saikat Mandal and Aditi Biswas - Conducting the study and writing the manuscript.

3.Dr. Anuradha De (Pati) - Guiding the study procedure, statistical analysis and preparing the manuscript suitable for publication.

Findings: Nil; Conflict of Interest: None initiated Permission from IRB: Yes

\section{References}

1. Roberts JM, Pearson G, Cutler J, et al. Summary of the NHLBI Working Group on Research on Hypertension During Pregnancy. Hypertension. 2003 Mar; 41(3): 437-45. Epub 2003 Feb 10. DOI:10. 1161/01. HYP.000005 4981. 03589.E9

2. Barton JR, O'brien JM, et al. Mild gestational hypertension remote from term: progression and outcome. Am J Obstet Gynecol. 2001 Apr;184(5):97983. DOI:10.1067/mob.2001.112905

3. Salgado SS, Pathmeswaran A. Effects of placental infarctions on the fetal outcome in pregnancies complicated by hypertension. J Coll Physicians Surg Pak. 2008 Apr;18 (4):213-6. doi: 04.2008/JCPSP. 213216. 
4. Udainia A, Jain ML. Morphological study of placenta in pregnancy induced hypertension with its clinical relevance. Journal of the Anatomical Society of India. 2001 Jun; 50(1): 24-7.

5. Udainia A. Bhagwat SS, Mehta CD. Relation between placental surface area, infarction and foetal distress in pregnancy induced hypertension with its clinical relevance. J Anat. Soc. Ind 2004; 53(1): 27-30.

6. Browne JC, Veall N. The maternal placental blood flow in normotensive and hypertensive women. J Obstet Gynaecol Br Emp. 1953 Apr;60(2):141-7.

7. Landesman R, Douglas RG, Holze E. The bulbar conjunctival vascular bed in the toxemias of pregnancy. Am J Obstet Gynecol. 1954 Jul;68(1):170-83. DOI:10.1016/0002-9378(54)90476-7

8. Thomson AM, Billewicz WZ, Hytten FE. The weight of the placenta in relation to birthweight. J Obstet Gynaecol Br Commonw. 1969 Oct;76(10):865-72.

9. Stock MK, Anderson DF, Phernetton TM, et al. Vascular response of the fetal placenta to local occlusion of the maternal placental vasculature. J Dev Physiol. 1980 Oct;2(5):339-46.

10. Majumdar S, Dusguspta $\mathrm{H}$, Bhattacharya $\mathrm{K}$, Bhattcharya A. A study of placenta in normal \& hypertensive pregnancies. J Anat. Soc. India 2005; 54(2): 1-9.

11. Wentworth P. Placental infarction and toxemia of pregnancy. Am J Obstet Gynecol.1967 Oct 1;99(3):318-26. DOI:10.1016/s0002-9378(16)34537-9

12. Joseph F Yetter III. Col, MC, USA, 'American family Physician' march 1998; Vol. 57 / No. 5 Published by American Academy Of Family Physician.

13. Benirschk. American Journal of Obstetrics and Gynaecology .1,New York 961;84:1595.

14. Shah R K et al. Journal of Obstetrics and Gynecology of India 1985;35:1809.

15. Shanklin D R. Journal of Obstetrics and Gynecology of the British Commonwealth 1958; 11: 129.

\section{Original Research Article}

16. Patricia C. Gray's Anatomy. 38th ed. New York: Churchill Livingstone,

17. Damania KR, Salvi VS, Ratnaparki SK, Daftari SN. The placenta in hypertensive disorder in pregnancy. $\mathrm{J}$ Obst and Gynaecol Ind 1989; 39: 28-31.

18. Fox $\mathrm{H}$; The placenta in intra uterine growth retardation. In Ward RHT, Smith SK, Donnai D (Eds). Early foetal growth and development. RCOG Press, London: 1994. p. 223-235.

19. Kalousek DK, Langlosis S. The effects of placental and somatic chromosomal mosaicism on foetal growth. In. Ward RHT, Smith SK, Donnai (eds), Early foetal growth and development, RCOG Press; 1994. p. 245256.

20. Mardi K, Sharma J. Histopathological evaluation of placentas in IUGR pregnancies. Indian $\mathrm{J}$ Pathol Microbiol. 2003 Oct;46(4):551-4.

21. Salgado SS, Angunawela P, Sirisena J, De Tissera A. Villous syncytial knots in hypertensive placentae. Sri Lanka J Obstet Gynaecol 2004; 26:33-7.

22. Fox H. Pathology of the Placenta. 2nd ed. W B: Saunders, London; 1997a

23. Benirschke K \& Kaufmann P. 'Pathology of Human Placenta' . 2nd ed. Newyork: Springer Verlag;1990. P. 130.

24. Soma H, Yoshida K, Mukaida T, et al. Morphologic changes in the hypertensive placenta. Contrib Gynecol Obstet. 1982;9:58-75.

25. Jones CJP, Fox H. An ultrastructural and ultrahistochemical study of the human placenta in maternal pre-eclampsia. Placenta 1980; 1:61-76.

26. Damjanov I, Linder J. Andersons Pathology.10th ed. New York: Mosby; 1906. p. 2321.

27. Tinney B Parker F. The placenta in Toxaemia of pregnancy. AmJ Obstet Gynecol 1940; 39: 1000-1005.

\section{How to cite this article?}

Bar PK, Ghosh S, Gayen P, Mandal S, De A. Morphological study of placenta in hypertensive disorders in pregnancy. Trop J Path Micro 2019;5(6):366-373. doi:10.17511/jopm.2019.i06.06. 